teaching and research of one of the Departments in the Faculty of Science. Prof. F. G. Holliman has been appointed to this post. He was educated at the County High School for Boys and Trinity College, Cambridge, where he obtained first-class honours in Parts I and II of the Natural Seience Tripos in 1941. During 1940-44 he was engaged on research into the compounds of arsenic; he was awarded the Alhusen Scholarship in 1942 and was elected a Fellow of Trinity College in the following year. In 1944 he was awarded the degree of Ph.D. of the University of Cambridge. During 1945-47 he held the post of demonstrator in the University of Cambridge, and in 1947 took up appointment as senior lecturer in organic chemistry in the University of Cape Town, where he was made professor of organic chemistry in 1950. He was awarded a Nuffield Fellowship in 1953 and spent the year working on the isolation of pigments in the Department of Organic Chemistry, University of Liverpool. In 1955 he became head of the Department of Chemistry in the University of Cape Town and during 1956-58 was Dean of the Faculty of Science, a post involving responsibility for the general organization, administration and formation of policy within the Faculty.

\section{Mathematics at Sussex : $\quad$ Prof. D. B. Scott}

There will be widespread interest in the recent announcement that Dr. D. B. Scott has been appointed to the chair of mathematics at the University of Sussex. Dr. Scott is forty-six years of age. He was educated at the City of London School and Magdalene College, Cambridge; a Wrangler, with distinction in Part III of the Mathematical Tripos; and he was awarded a Rayleigh Prize in 1939 for work done under the supervision of Prof. W. V. D. (now Sir William) Hodge. After a short period as assistant master at St. Olave's and St. Saviour's Grammar School, London, a period as assistant lecturer at Queen Mary College, London (interrupted by four years in Room 17 at the Foreign Office), and a fleeting sojourn in the University of Aberdeen, he started in 1947 his fifteen-year period of service in the Department of Mathematics at King's College, London. In 1951 he was awarded the Junior Berwick Prize of the London Mathematical Society for distinguished work on the theory of point-curve correspondences on an algebraic surface, and in 1953 the title of reader was conferred on him by the University of London. Dr. Scott's wide reputation as an algebraic geometer of the modern school rests largely on a series of very elegant papers dealing with valency correspondences on algebraic surfaces and also on his recent work on tangent-bundles of algebraic varieties. It owes much, however, to his high personal standards and to his versatile personality; and it has been further enhanced by the virtuosity of his public performances as a skilled and highly spirited exponent of present-day developments in his subject. He has had some very successful research pupils in London, and has done much, in collaboration with these and others, to direct and develop the advanced study of algebraic geometry in the University. On the departmental side, Dr. Scott is outstanding in the active interest he has always taken in his students, their progress and subsequent careers. The selection of Dr. Scott to direct the inauguration and development of the Department of Mathematics in the University of Sussex will be approved by all who know him as being in every way fortunate and admirable.

\section{Proposed National Resources Council}

In the leading article on the Report of the Advisory Council on Scientific Policy 1959-60 (Nature, 188, $438 ; 1960)$, we noted that the Council was considering whether a need did not exist for a new Research Council to bear the central and general responsibility for scientific matters relating to the conservation of our natural resources. In the Council's view, there was a significant absence of basic research in the scientific assessment of such major problems as the conservation and long-term utilization of water supplies and land, and in such questions as relate to long-term climatic changes. The Council then set up a Working Party on Water Conservation and Land Use, which held discussions with the Departments principally concerned with research on water conservation. After a further preliminary review of the whole position, the Council has constituted a new committee, under the chairmanship of Sir William Slater, formerly secretary of the Agricultural Research Council, to consider the implications of the establishment of a Natural Resources Council. This committee will take evidence from all interested quarters before submitting its report. Other members of the Committee are : Sir Solly Zuckerman, scientifio adviser to the Minister of Defence; Sir Lindor Brown, professor of physiology in the University of Oxford; Mr. F. C. Bawden, director of Rothamsted Experimental Station; and Prof. C. H. Waddington, professor of animal genetics in the University of Edinburgh.

\section{Institute of Mathematical Sciences, Madras}

AN Institute of Mathematical Sciences for the pursuit of advanced study and research in all branches of mathematics and theoretical physics has been established in Madras by the Government. The aims and objects of the new Institute are similar to those of the Institute for Advanced Study, Princeton, that is, to provide an atmosphere and an environment suitable for creative work and the pursuit of learning for its own sake. Facilities will be offered to visiting scientists who will be invited as professors or members to spend considerable time in the Institute and work in collaboration with the members of the permanent staff. In the first instance, it is proposed to have four faculties: theoretical physics, astrophysics, mathematics and applied mathematics. Dr. Alladi Ramakrishnan, hitherto professor of theoretical physics in the University of Madras, has been appointed as first professor of the Institute. Prof. S. Chandrasekhar, Distinguished Service professor of astrophysics, Enrico Fermi Institute of Nuclear Studies, University of Chicago, has been appointed honorary professor of astrophysics.

\section{Financial Incentives}

Financiat incentive schemes are regarded as effective means of increasing co-operation between workers and management. The evidence suggests, however, that their effectiveness is limited and that they are likely to be less-widely applied as productive techniques improve. This is the conclusion reached in Money for Effort, by Tom Lupton, in one of the Department of Scientific and Industrial Research Problems of Progress in Industry sories (H.M.S.O., 1961. Price $1 s .9 d$., by post $2 s$. $1 d$.). The author discusses the evidence that is available from studies of the working of incentive schemes over a number of years. He shows that 33 per cent of British workers are paid according to some kind of financial incentive, which is an increase of 4 per cent since 1939. This 